Supplement of Saf. Nucl. Waste Disposal, 1, 121-123, 2021

https://doi.org/10.5194/sand-1-121-2021-supplement

(c) Author(s) 2021. CC BY 4.0 License.

Supplement of

\title{
Compaction of crushed salt for safe containment - overview of the KOMPASS project
}

\section{Larissa Friedenberg et al.}

Correspondence to: Larissa Friedenberg (larissa.friedenberg@grs.de)

The copyright of individual parts of the supplement might differ from the article licence. 


\section{Compaction of crushed salt for the safe containment - Overview of the KOMPASS project}

L. Friedenberg ${ }^{1}$, J. Bean ${ }^{5}$, O. Czaikowski ${ }^{1}$, U. Düsterloh ${ }^{6}$, B. Laurich ${ }^{3}$, Ch. Lerch², Svetlana Lerche ${ }^{6}$, Ch. Lüdeling ${ }^{4}$, M. Mills ${ }^{5}$, N. Müller-Hoppe ${ }^{2}$, T. Popp ${ }^{4}$, B. Reedlunn', D. Stührenberg' ${ }^{3}$, K. Svensson ${ }^{3}$, K. Zemke ${ }^{3}$, J. Zhao ${ }^{6}$

${ }^{1}$ Gesellschaft für Anlagen- und Reaktorsicherheit (GRS) gGmbH, Theodor-Heuss-Straße 4, 38122 Braunschweig, Germany

${ }^{3}$ Federal Institute for Geosciences and Natural Resources (BGR), Stilleweg 2, 30655 Hannover, Germany

${ }^{5}$ Sandia National Laboratories, New Mexico, 1515 Eubank SE, Albuquerque, New Mexico 87123, USA

2BGE TECHNOLOGY GmbH, Eschenstraße 55, 31224 Peine, Germany

${ }^{4}$ Institut für Gebirgsmechanik GmbH, Friederikenstraße 60, 04279 Leipzig, Germany

${ }^{6}$ Clausthal University of Technology, Erzstraße 20, 38678 Clausthal-Zellerfeld, Germany

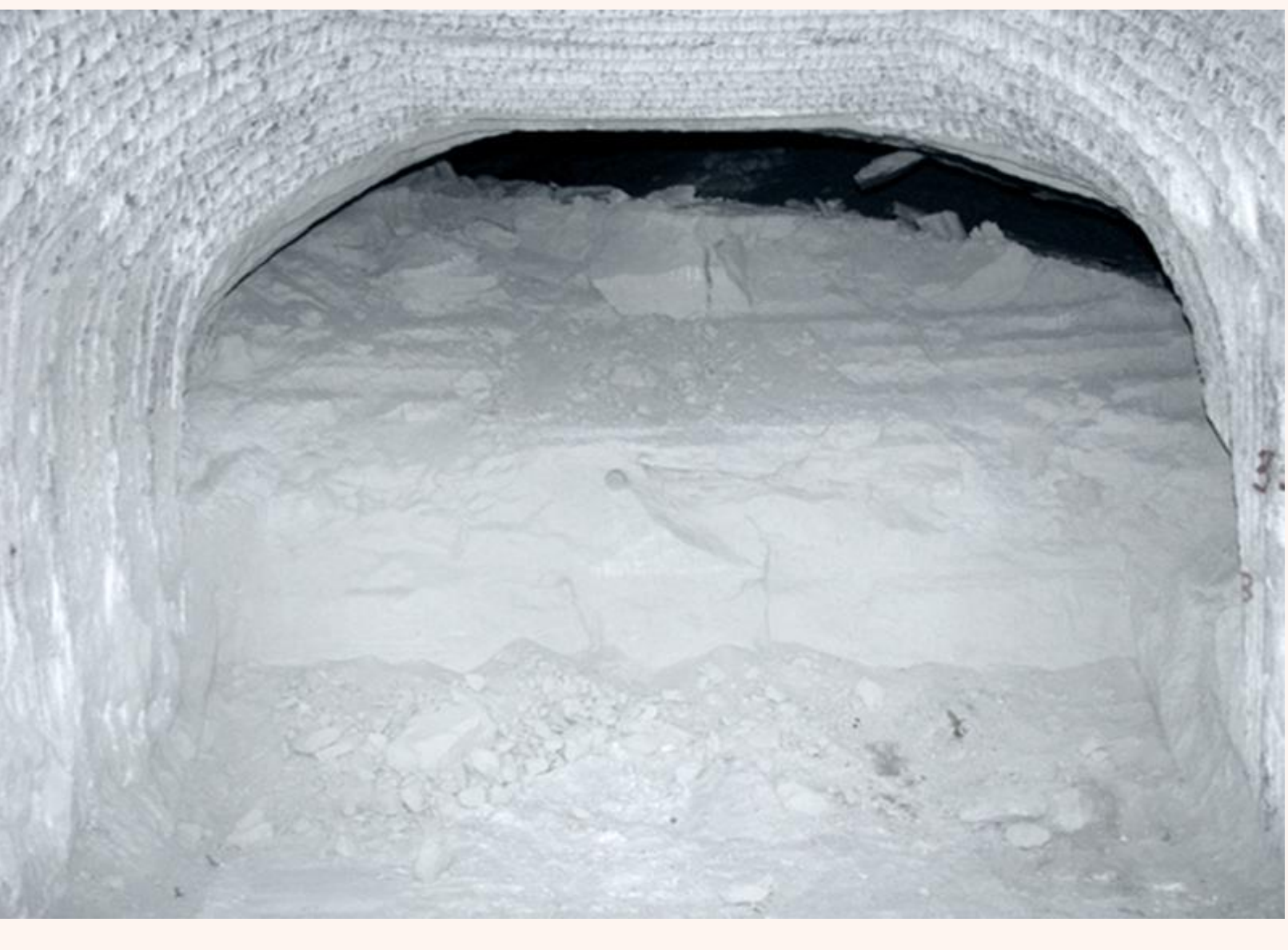

\section{Role of crushed salt in a possible rock salt repository:}

- Backfill for cavities and sealing measures

- Barrier function: compaction state as equivalent parameter for porosity reduction

- $\quad$ Porosity/permeability relationship $\rightarrow$ input for long-term safety

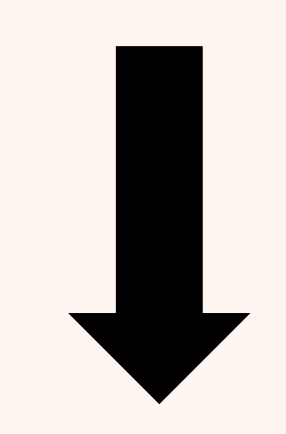

\section{KOMPASS objective:}

Development of methods and strategies for the reduction of deficits in the prediction of crushed salt compaction $\rightarrow$ Improvement of prognosis quality

\section{Experimental investigations:}

- KOMPASS reference material

$>$ Easy available \& permanent producible

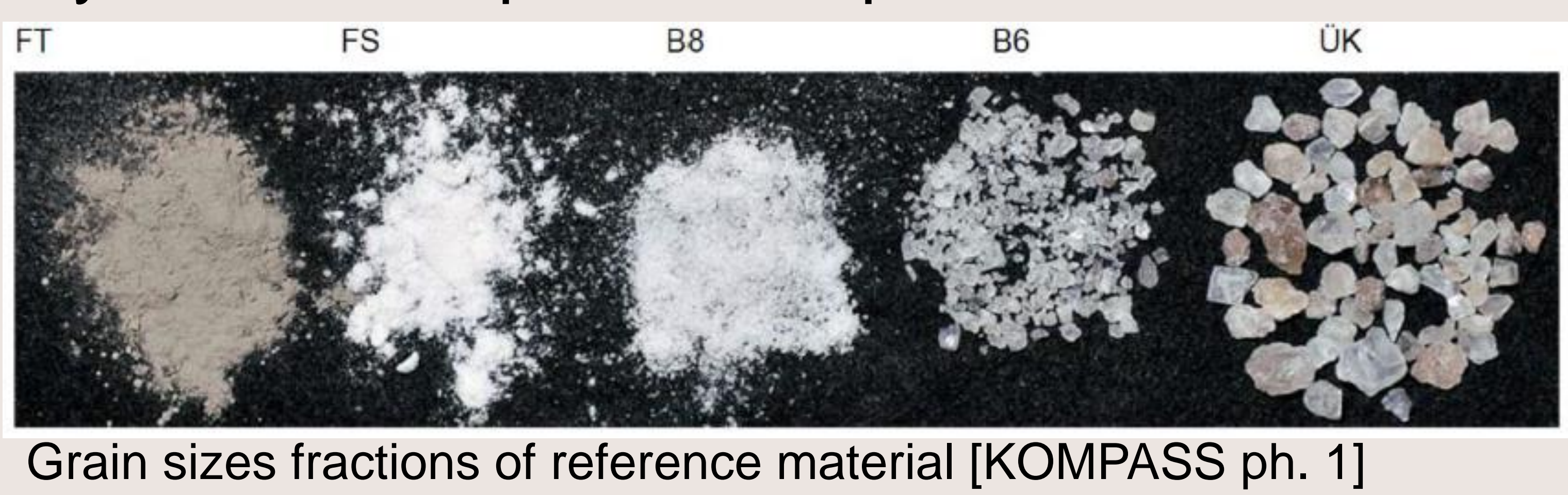

- Pre-compaction

$>$ Producing samples with in-situ comparable grain structure
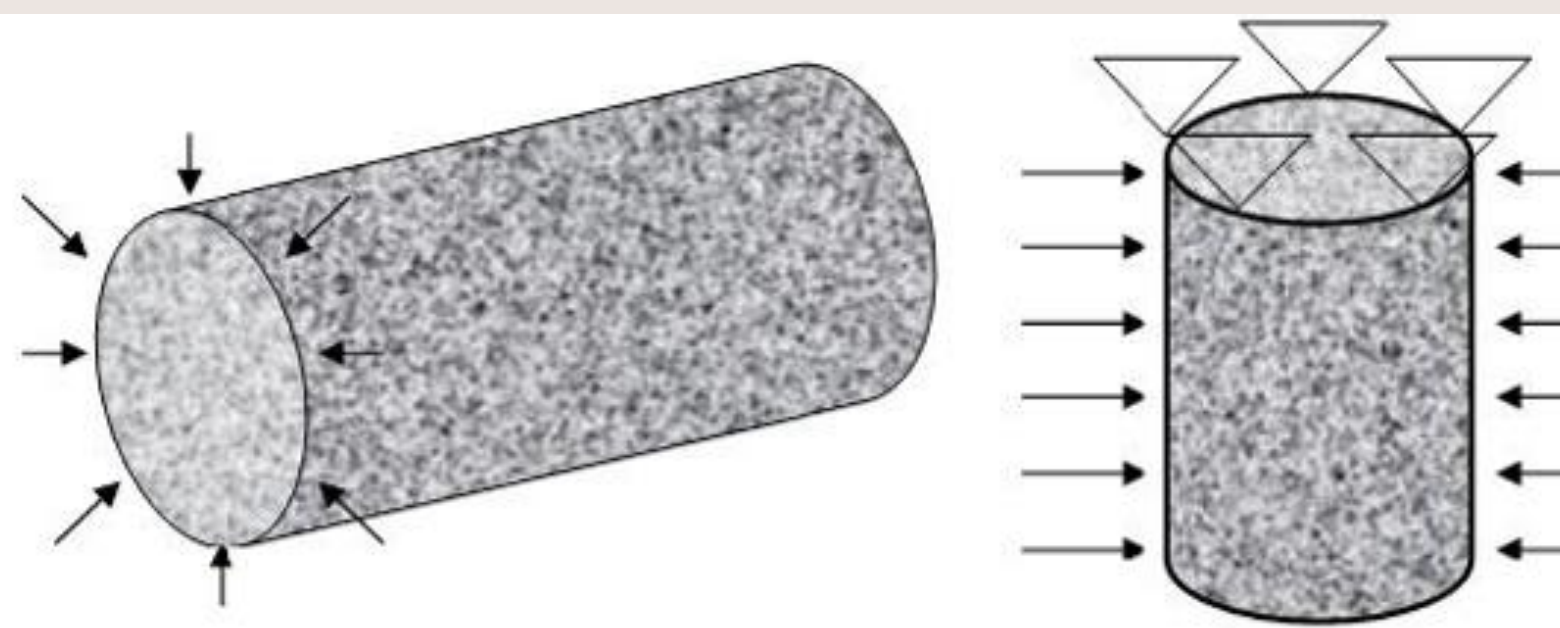

Plane-strain compaction [KOMPASS ph. 1]

- Long-term compaction

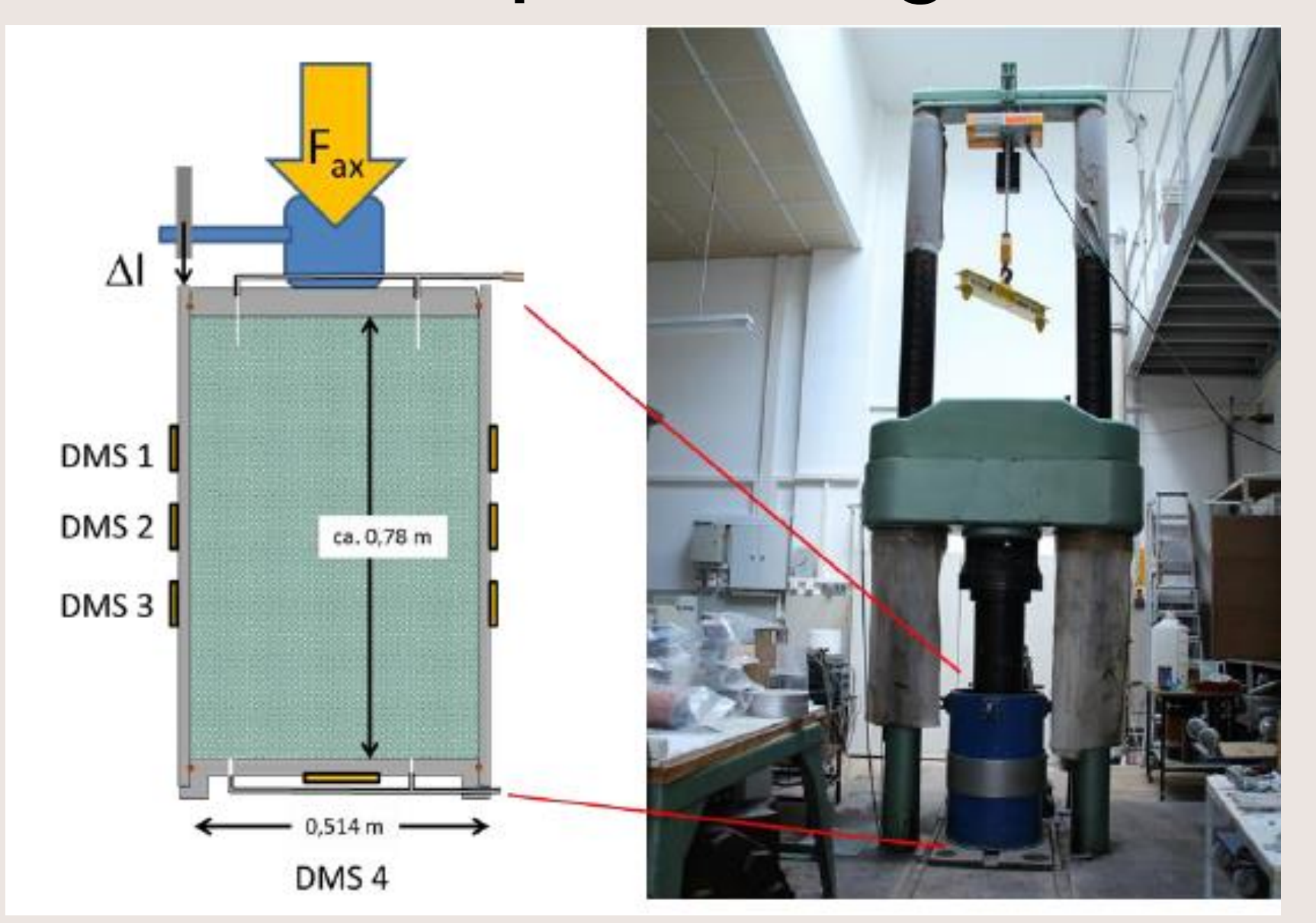

Big oedometer cell [KOMPASS ph. 1]

\section{Microstructural investigations:}

- Enhancement of process understanding

- Association of microstructures with deformation mechanism

- Influence of humidity

- Verification of pre-compacted methods

- Investigation of loose crushed salt, pre-compacted samples \& long-term compacted samples

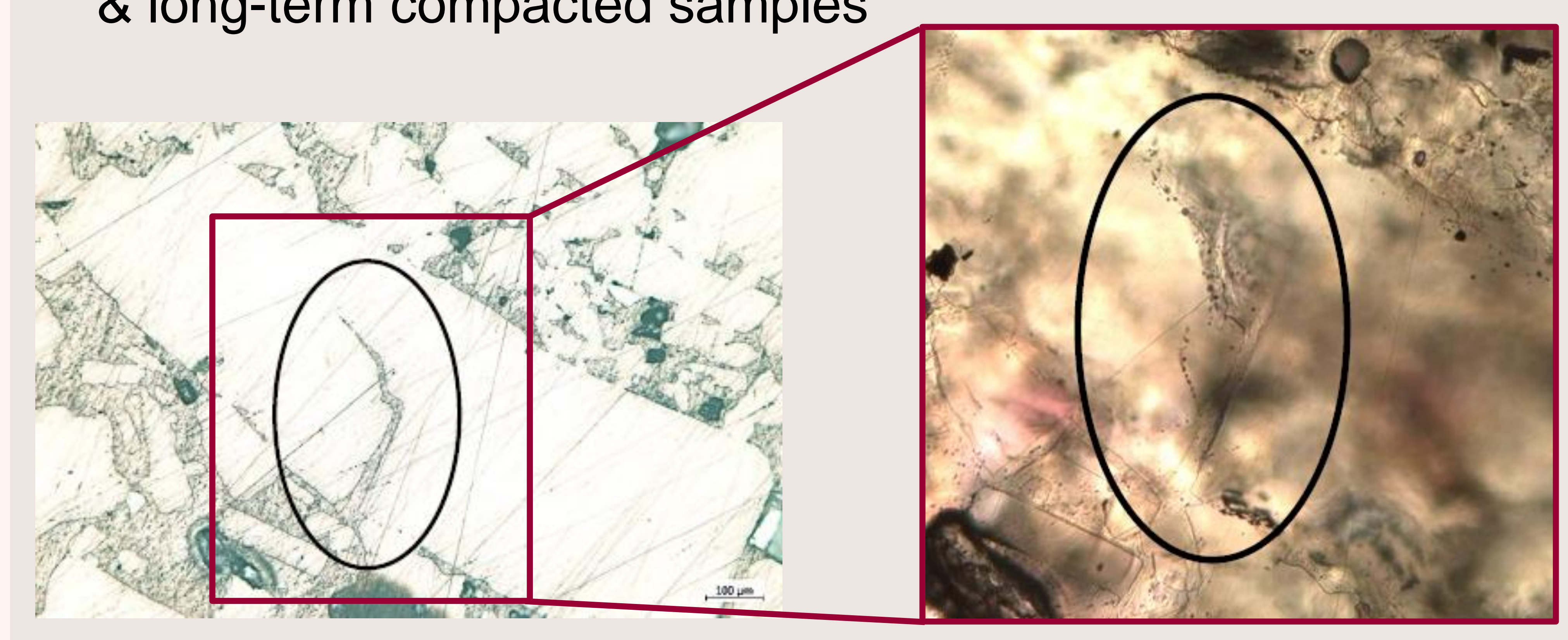

Left: crack propagation through a grain; Right: fluid inclusions near the crack propagation [KOMPASS ph. 1]

$>$ Development of a systematic program

$>$ Isolated investigation of influencing factors

\section{Numerical strategies:}

- Analysis of various constitutive models

- Benchmarking of three triaxial long-term tests

$>$ Results were not entirely satisfactory

$>$ Further validation work has to be done

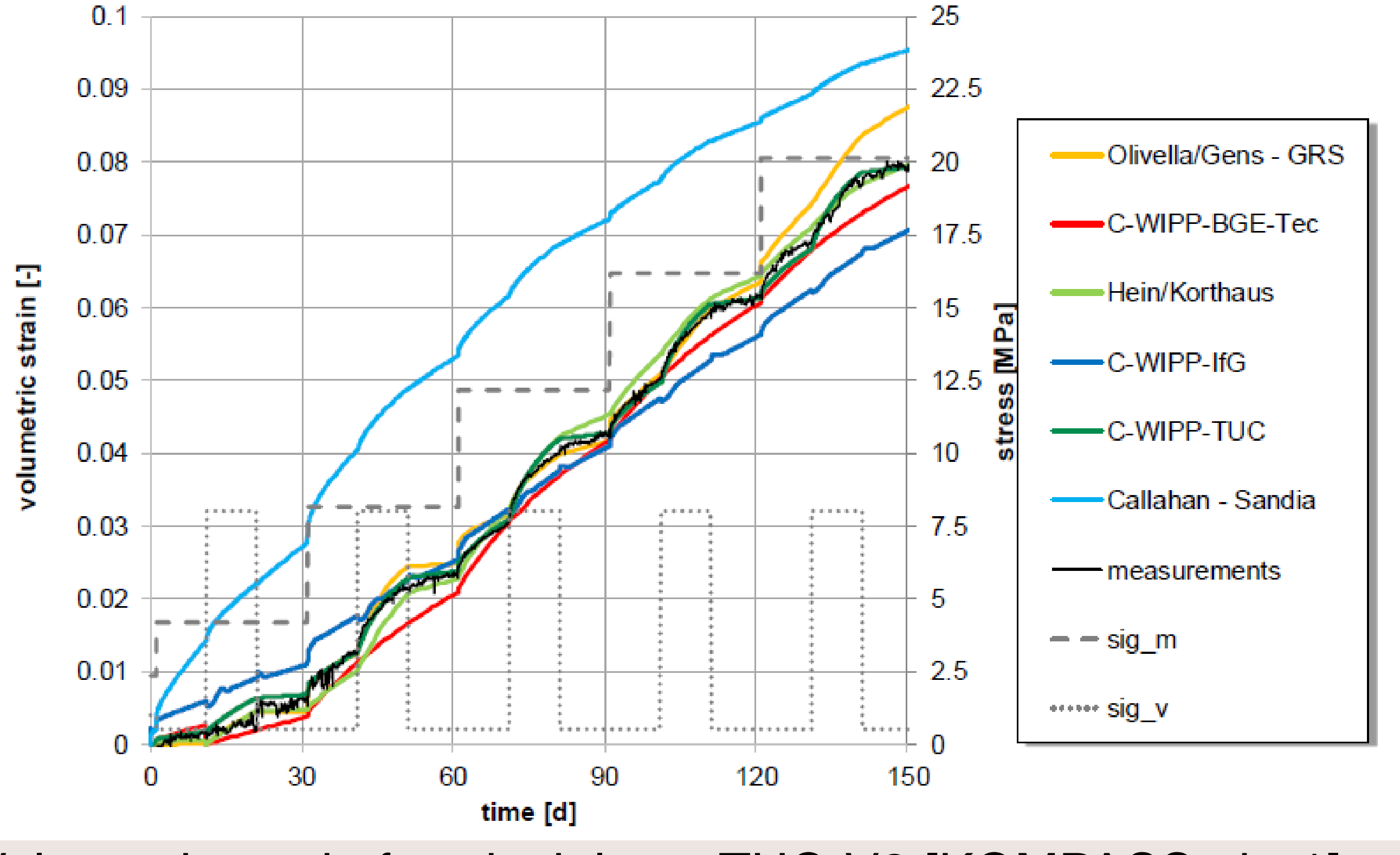

Volumetric strain for triaxial test TUC-V2 [KOMPASS ph. 1]

[KOMPASS ph. 1]

Czaikowski, O., Friedenberg, L., Wieczorek, K., Müller-Hoeppe, N., Lerch, Ch., Eickemeier, R., Laurich, B., Wenting, L., Stührenberg, D., Svensson, K. Zemke, K., Lüdeling, Ch., Popp, T., Bean, J., Mills, M., Reedlunn, B., Düsterloh, U., Lerche, S., Zhao, J.: Compaction of crushed salt for the safe containment. KOMPASS project. Gesellschaft für Anlagen- und Reaktorsicherheit (GRS) gGmbH. GRS-608. Köln, 2020

This poster refers to the outcomings of the first phase of KOMPASS: 01.09.2018 31.08 .2020

\section{Supported by:}

Federal Ministry for Economic A
and Energy
(0) Us: ENERG

NDSOS 